\title{
'We are not blaming anyone, but if we don't know about amenities, we cannot seek them out': black and minority older people's views on the quality of local health and personal social services in England
}

\author{
JILL MANTHORPE*, STEVE ILIFFE $\dagger$, JO MORIARTY*, \\ MICHELLE CORNES*, ROGER CLOUGH**, LES BRIGHT $\dagger \dagger$, \\ JOAN RAPAPORT** and OPRSI †*
}

\begin{abstract}
Improving access to culturally-appropriate services and enhancing responses to the needs of older people from black and minority ethnic backgrounds were among the aims of the National Service Framework for Older People (NSFOP) that was introduced in England in 200I. Progress in meeting the aims of the NSFOP was evaluated by a mid-term independent review led by the Healthcare Commission, the body responsible for regulating health-care services in England. This paper reports the consultation with older people that underpinned the evaluation. It focuses on the views and experiences of older people from black and minority ethnic (BME) groups and of the staff that work in BME voluntary organisations. A rapid appraisal approach was used in Io purposively selected local councils, and plural methods were used, including public listening events, nominal groups and individual interviews. In total 1,839 older people participated in the consultations and I,280 (70\%) completed a monitoring form. Some 30 per cent defined themselves as of a minority ethnic background. The concerns were more about the low recognition of culturally-specific and language needs than for the development of services exclusively for BME older people.
\end{abstract}

KEY WORDS - black and minority ethnic older people, UK National Service Framework for Older People, consultation, health services, social care.

* Social Care Workforce Research Unit, King's College London, UK.

$\dagger$ Department of Primary Care and Population Sciences, University College London, London, UK.

** Eskrigge Social Research Ltd, Gressingham, Lancaster, UK.

$\dagger \dagger$ Independent Consultant, Exeter, UK.

$\dagger^{*}$ Older People Researching Social Issues, UK. 


\section{Introduction}

'Public bodies cannot meet the full range of needs which exist for their services unless they recognise, value, and address the diversity of the society which they serve' (National Audit Office 2004: 3), but many studies have documented the difficulties faced by minority ethnic older people in the United Kingdom (UK) in accessing culturally-appropriate health and personal social services of satisfactory quality (Butt and Mirza ig96; Katbamna et al. 2004; Lashko 2006; Levenson and Meredith 2000; Policy Research Institute on Ageing and Ethnicity (PRIAE) 2005). A similar picture appears elsewhere. Whilst it is accepted that there is a widespread need and indeed obligation to develop culturally-sensitive and responsive services for the increasingly diverse communities of older people from minority ethnic groups in Europe, the spread of such services is slow (Warnes et al. 2004). This paper uses data from an evaluation of the National Service Framework for Older People (NSFOP) (Department of Health 200I) carried out by the Healthcare Commission, the body responsible for regulating health-care services in England (Healthcare Commission $2006 a$ ). It reports on the experiences of people aged 50 or more years from black and minority ethnic groups, and describes the issues that they identified about access to and the responsiveness of health and social services. It concludes by drawing lessons about the cultural sensitivity of services for older people from diverse ethnic backgrounds, and about involving older people from minority ethnic groups in evaluations of health and social care services.

A mixed methodology for the consultation was used to build a picture of service performance at the local level and to guide interventions to improve service commissioning and delivery. This paper reports on a secondary analysis of the data with the purpose of focusing on the views and experiences of older people from black and minority ethnic (BME) groups and of the staff that work in BME voluntary, community or thirdsector organisations. Themes relevant to ethnicity, service provision and cultural sensitivity and the expectations of the NSFOP are discussed in this paper.

\section{Background}

The National Service Framework for Older People was introduced in England by the Department of Health in 200I, as a template for decade of reform of services for older people in the National Health Service (NHS) and local council services, including social care or personal social services 
T A B L E I. Components of the National Service Framework for Older People related to black and minority older people

\begin{tabular}{|c|c|}
\hline Standard & Item \\
\hline Introduction & $\begin{array}{l}\text { Acknowledgement of growing proportions of older people from } \\
\text { black and minority ethnic (BME) groups (para Io) } \\
\text { Recognition of greater prevalence of some long-term conditions } \\
\text { among minority ethnic groups (para II) } \\
\text { Call for services to be culturally appropriate (para I2) }\end{array}$ \\
\hline $\begin{array}{l}\text { Standard } \mathbf{r}: \\
\text { Rooting out age } \\
\text { discrimination }\end{array}$ & $\begin{array}{l}\text { Recognition of increased risk of disadvantage among older people } \\
\text { from BME groups (para I.5) } \\
\text { Identification of BME groups' greater disadvantage in accessing } \\
\text { services (para I.7) }\end{array}$ \\
\hline $\begin{array}{l}\text { Standard 2: } \\
\text { Person-centred care }\end{array}$ & $\begin{array}{l}\text { Requirement to recognise individual differences and specific needs } \\
\text { such as cultural and religious differences (para 2.I) } \\
\text { Call for greater availability of interpreting and translation services } \\
\text { Call for information to be made available in a range of languages } \\
\text { (para 2.I5) } \\
\text { Call for good assessment not be culturally biased, and for staff } \\
\text { to make sense of the ways in which race, culture and religion } \\
\text { may affect a person's needs and may impact upon each other } \\
\text { (para 2.3I) }\end{array}$ \\
\hline $\begin{array}{l}\text { Standard } 7 \text { : } \\
\text { Mental health service } \\
\text { specialisation and improvement }\end{array}$ & $\begin{array}{l}\text { Recognition that mental health services for people from minority } \\
\text { ethnic communities should be accessible and appropriate (para } 7 \cdot 3 \text { ) } \\
\text { Demand that mental health services should enhance trust by } \\
\text { not being culturally biased, and that information should not just } \\
\text { be available in translation (para } 7 \cdot 3 \text { ) }\end{array}$ \\
\hline $\begin{array}{l}\text { Standard 8: } \\
\text { Health promotion }\end{array}$ & $\begin{array}{l}\text { Call for health promotion activity to acknowledge differences in } \\
\text { lifestyles and the impact of cultural/religious beliefs } \\
\text { Call for health promotion services to be devised in conjunction } \\
\text { with local BME communities (para 8.3) }\end{array}$ \\
\hline
\end{tabular}

Source: Department of Health 200 .

(Department of Health 200I). The NSFOP called for a re-orientation of public services so that all older people and their carers would be treated with respect, dignity and fairness, and their health and independence promoted (see Manthorpe et al. 2007). In setting out these standards, and in contrast to many earlier policy documents concerned with ageing, such as A Happier Old Age (Department of Health and Social Security and Welsh Office I978), Growing Older (Secretaries of State for Social Services, Scotland, Wales and Northern Ireland I98I), and Caring for People (Secretaries of State for Health and Social Security, Wales and Scotland I989), the NSFOP highlighted the need for health and social care services to respond to the socio-cultural heterogeneity of older people, and in particular the need to improve services for people from black and minority ethnic groups. These ambitions are summarised in Table I, which 
illustrates how the case for change was built on the rationale of greater diversity among older people.

\section{An enduring issue}

The issues highlighted in the NSFOP were not new. During the I970s efforts had been made to identify the health and social care needs of older people from minority ethnic groups (Coombe i978; Blakemore and Bhalla 1979), raising the question why, if the need for providing accessible and culturally-appropriate services has been established for so long, has this proved so elusive. Perhaps the most important reason is that the relationship between health and ethnicity in old age is complex. While there is now a sharper focus on the health-risk factors specific to British minority ethnic groups (Ahmad and Atkin 1996; Lowdell et al. 2000; Nazroo 200 ; Rait and Iliffe 2003), there is also a growing body of evidence that ethnic inequalities in health are largely a consequence of socio-economic differentials, to which racism and the perception of living in a racist society may contribute (Nazroo and Williams 2005). For example, Ahmad and Walker (1997) found that older Asian people in the City of Bradford (West Yorkshire) were more likely to be living in poorer quality housing than their white counterparts. Similarly, Lowdell et al. (2000) found that older people from minority ethnic groups living in London, with the exception of some Indian older people, were more likely to be over-represented in the lowest 20 per cent of the income range.

There is, however, increasing recognition of the diversity of Britain's minority ethnic groups and of the variations within as well as between them (Mason 2003; Iliffe and Manthorpe 2004). These may create quite different, and changing, patterns of need between localities. For example, it has been predicted that the number of older people aged 75 or more years in the City of Bradford in the Pakistani-origin community will increase by I82 per cent between the years 200I-2010, but that the number of older people from black Caribbean groups will fall (Simpson 1997; City of Bradford Policy and Research Unit I999; Warnes, Lowles and Oh 2002). Another reason for the failure to achieve better services is the variable way that public services have responded to the low uptake of health and social services by older people from black and minority ethnic groups. The Audit Commission (2004) ascribed such problems to institutional barriers, including the low priority given to race equality, the belief that it was not an issue affecting every local community, and the difficulties in engaging with older people from black and minority ethnic groups. 
The Social Services Inspectorate (latterly the Commission for Social Care Inspection), the body responsible for regulating social care services, drew together information from inspection and monitoring reports and concluded that, 'almost all the councils inspected had gaps in their provision for meeting needs arising from minority cultures'; it was particularly critical of councils that justified this by claiming that few black and minority ethnic group older people lived in their locality (Bainbridge and Ricketts 2003: 4). This problem is not confined to local councils. A Healthcare Commission (2006 b: 2I) report concluded that many of the negative experiences of NHS care experienced by people from minority ethnic groups could 'mean that staff in the NHS are not taking account of cultural differences and sensitivities when they are treating patients'.

In the United Kingdom some specialist services for black and minority ethnic people have developed precisely because of the failure of mainstream services to meet their needs (Butt and Mirza 1996). It should not be assumed that their absence would mean that mainstream services would become any more effective at delivering suitable services. In particular, the experience of racism in mainstream services has been a powerful reason why some minority ethnic older people have been reluctant to use them (Butt and O'Neil 2004). While the Royal Commission on Long-Term Care (1999: para 8.35) suggested that more responsive and culturally-appropriate mainstream services would reduce the demand for specialist services, the corollary is that this cannot happen without making changes to the quality of mainstream services. Better ways of consulting and engaging with older people from minority ethnic groups have been identified as ways of meeting this policy goal (Bainbridge and Ricketts 2003).

\section{Consulting black and minority ethnic communities}

Engagement with black and minority older people was an important methodological challenge for the research presented here-issues of participation relate to research as well as policy. First, and predictably, trust is important for engagement. Many black and minority ethnic groups have negative perceptions of local councils and view existing representative structures as insufficiently effective or independent from official authorities (Bousetta 200I). Secondly, individual black and minority ethnic older people continue to experience language and communication problems that exclude them both from services and from becoming involved in making decisions about them (PRIAE 2005: 17). Thirdly, the growing 
diversity among black or minority ethnic communities has increased awareness of groups that are 'seldom heard' (Iliffe and Manthorpe 2004). These include recent arrivals to the UK (Butt 2005), such as some older refugees (Connelly et al. 2006), and those with a longer history of social exclusion, such as travellers (Parry et al. 2004). Other groups may be excluded because they are numerically smaller and concentrated in certain localities, such as Greek Cypriots (Anthias I992), or are extremely dispersed, such as Chinese older people (Yu 2000). Other 'seldom-heard' older people include those who are not always perceived as differing from the White British community, such as the Irish or Polish.

Consultation does not take place in a social vacuum and the fourth barrier to better consultation arises from the growing evidence of the complexity of groups and associations that work with black and minority ethnic older people. The organisations that represent people from minority ethnic groups vary in size, resources and the extent to which they represent all groups in their community (Department for Communities and Local Government 2007: 7). One survey identified 5,500 black and minority ethnic voluntary organisations (excluding faith groups) in England and Wales (McLeod, Owen and Khamis 200I). Taken together, the picture outlined above highlights some of the complexities surrounding the evaluation of progress in improving health and social care services for older people from black and minority ethnic groups.

\section{Methods}

A series of consultations with older people, including service users and carers, was undertaken with the aim of informing the evaluation of the NSFOP (Healthcare Commission 2006a). These took place in io local council areas within which there were 40 NHS Trusts. ${ }^{1}$ A rapid appraisal approach was used to explore the impact of the NSFOP on local services, in response to the Healthcare Commission's brief. This approach involves communities in identifying their own needs, and is a common means internationally of evaluating improvements in health and wellbeing (World Health Organisation 1992). It can provide timely, relevant information that contextualises unsatisfied needs in local social structures and service cultures (Ong et al. I99I). Although rapid appraisal methods can include quantitative data collection, the dominant approach is qualitative, to capture the perspectives and experiences of those using services (Murphy et al. 1998). Rapid appraisal requires plural and mixed methods (in this case, public listening events, nominal groups and individual 
interviews) that purposively allow for the possibility of conflicting or differing judgements about success (Jee et al. I999). External stakeholder consultations were also undertaken with representatives from the voluntary and community sectors in each of the io localities. The methodology of this rapid appraisal study is described in detail elsewhere (Manthorpe et al. 2007; Moriarty et al. $2007 a){ }^{2}$

To address the risks of bias and generalisation, a standard approach to the consultation process was adopted and tailored to each locality. We took advice on local networks and sought a collaborative approach with representatives of older people. In each of the io inspection sites, researchers worked initially with local voluntary and community groups. Where groups had good relationships with older people from black and minority ethnic communities, they were offered a consultancy fee to provide guidance and support to the researchers on a wide range of practical issues, such as venues, appropriate refreshments, and how to find the best local interpreters. Written information was translated into several languages and circulated in advance as posters and leaflets. While good use of local media was made, the recruitment of older people from minority ethnic communities was most helped by the willingness of local groups to undertake outreach work person-to-person that promoted awareness of the evaluation. To monitor the demographic profile of those who agreed to take part, a brief form collected details of gender, age and ethnicity.

In each local council area, a meeting was convened with representatives from the local voluntary and community organisations that work with older people. In some areas, this included established minority ethnic groups, but in others a more direct strategy was required to collect the views of older people from certain backgrounds. This included approaches to local Race Equality Councils, using directories of older people's groups, and 'snowballing' with representatives from influential voluntary and community groups. The success of these approaches was variable, which underlines the importance of multiple methods. For example, responses from local Race Equality Councils ranged from very helpful - a senior member of staff personally contacted local groups, arranged transport, and interpreted two discussion groups - to refusals to be involved. Using multiple sources also facilitated contacts with seldom-heard groups, such as the Somali, West African, Polish and other Central European communities, and with different faith communities such as Hindus, Muslims, Sikhs and Jewish people. By involving multiethnic social groups in social or service settings, such as day centres and clubs for older people, contacts with community and faith groups in each of the ro local authority areas enabled the participation of older people 
from Irish, Indian, Afro-Caribbean, Bosnian, Nigerian, Chinese, Indian, Yemeni, Vietnamese and Punjabi backgrounds. All consultations (listening events, nominal groups and interviews) were conducted using a semistructured guide to the themes of the evaluation (Manthorpe and Klee 2006). The questions were agreed with the Healthcare Commission and piloted with the panel of older researchers who formed part of the research team, Older People Researching Social Issues (OPRSI) (Leamy and Clough 2006). The following questions and sub-questions were asked:

I. Are there specific local concerns about health, social and local council services? How do these affect health and wellbeing?

2. Have you used local NHS or council services in the last five years? If yes, what were your experiences?

3. How well do local health and social services provide older people and their families with help and support?

4. How do NHS and council staff treat older people and their carers? How could local NHS and council services be improved?

5. What part do older people and carers play in planning and developing local services?

The consultation events and opportunities were publicised through organisations for older people. Accessible venues were arranged and both plenary and small-group sessions were included at all events. Transport was provided, if desired, refreshments were available, there was time for breaks, and individuals' expenses were refunded in cash on the day. Particular attention was paid to personal welcomes, participants' comfort and sense of ease. Facilitators from OPRSI led all small groups (described below) with a remit to involve all participants. Interpreters assisted with communication, both with those whose first language was not English and for those whose hearing or speech was impaired. The informants were asked about all their own experiences of using public services during the previous 12 months. Accounts of an older family member's or close friend's experiences were also collected, but not hearsay or generalisations.

The group consultations used a modified nominal group technique (NGT), which is a structured group interview that allows for the generation of ideas and addresses some of the problems of more informal groups, such as their domination by certain members and a few ideas (Delbecq and Van de Ven I97I; Drennan et al. 2007). Nominal group techniques are useful in identifying people's perspectives (Gallagher et al. 1993), have strong validity and are more acceptable than some other 
forms of consultation (Ryan et al. 200I). Each group was co-facilitated by members of the research team experienced in nominal group methods, with an observer to take detailed notes on the group processes as well as the content of what was discussed. Individual interviews were also undertaken to gain more information about 'insider perspectives' and about how local services functioned. These interviews took place with older people who were recruited through contacts at listening events and nominal groups, in response to invitations issued through voluntary and community groups and local media, and by 'snowballing' methods. A sample of interviews was tape-recorded and transcribed.

Quality assurance of the whole consultation process was implemented by: (I) training OPRSI members in the semi-standardised enquiry method; (2) briefing and de-briefing following data collection, and with the interpreters; (3) observation by the research team leaders; (4) the multi-disciplinary analysis of findings. In each locality the data were reviewed by the multi-disciplinary research team and OPRSI. The team used an explicit analytic induction technique (Ragin 1994), which identifies commonalities across the various sources of data. Analytic induction (AI) is defined as the intensive examination of a strategically selected number of cases so as to establish empirically the causes of a specific phenomenon. Intrinsic to the approach is the 'public' readjustment of definitions, concepts, and hypotheses (Manning I982: 283). In this study a modified AI technique, influenced by the accounts described by Johnson (2004) and Bondas (2006), was used to compare informants' accounts and to identify similarities and differences, thereby constructing the uniformities underlying and defining the emergent categories.

Shared features from the group or individual accounts were used to generate 'messages' or categories around which local and national reports (for the Healthcare Commission) could be compiled. To exemplify, calls for 'seamed and seamless services: negotiating health and social care' linked the participants' concerns about the lack of integration of services, and the theme 'managing daily living' referred to the things that mattered to the participants in managing their daily routines but which were not always high priorities for the health and care services, such as finding a gardener. 'Deviant' cases were re-examined and in some cases either the messages were re-categorised or categorised as 'mini messages'. Thus, while the main topics concerning which participants were asked to describe their experiences had been defined by the funder, the participants' own concerns and priorities were recorded and analysed. Those themes relevant to ethnicity, service provision and cultural sensitivity and the expectations of the NSFOP are discussed in this paper. 


\section{Findings}

In total, I,839 older people participated in the consultations and I,280 (70\%) volunteered to complete monitoring forms. Of those, some 30 per cent defined themselves as from a minority ethnic background (Table 2). The proportion of older people from minority ethnic communities ranged from less than one per cent at one site to 79 per cent at another. The variation broadly reflected the regional and local composition of the population at the different study locations (Office for National Statistics 2002; Peach 2005). The themes that arose in response to the five questions are italicised in the following discussion.

\section{Specific local concerns}

A consistent theme across localities was that there were problems in obtaining information about services. While such opinions were voiced by many older people, some minority ethnic group representatives and individuals consistently raised the issue of a dearth of translation. One older woman said (in translation), 'There is a lack of information. Letters translated in [our] languages posted to our houses, telling us about the services would help. There needs to be more talks and sessions so we know what services we can get'. A group representative added:

There is lack of information in Gujarati on benefits, social and health-care services to this particular over-5os women's group. The women say that there is no system where they can just pick up the phone and get help from services.

Improving access to information was not seen simply as translating copies of leaflets into community languages but, more broadly, as a need to improve the content for all older people including those who spoke English. Making the content relevant to different communities was suggested by a group of older people from West Africa, amongst others, who expressed in various ways that 'their specific needs are not always recognised', there is 'a need for special awareness pamphlets to strengthen and build up individual and community well-being', and 'if we don't know about amenities we cannot seek them out'.

The adequacy of interpreting and translation services was explored. Asked in her mother tongue if the hospital translation service was good, an older woman replied, 'Yes, not bad, I have to call a few days before [to make arrangements]'. The group leader commented, however, that 'there is only one translator for each language, so you have to wait, you cannot call the same day.... The service would be improved if you could call to book the same day'. Another group leader commented that interpretation services needed to be aware that some older people might 
T A B L E 2. Self-reported ethnicity of the participants who completed a monitoring form

\begin{tabular}{|c|c|c|c|c|c|c|c|c|c|c|c|}
\hline \multirow[b]{2}{*}{ Ethnic group } & \multicolumn{11}{|c|}{ Population and socio-economic characteristics of the review local authority } \\
\hline & $\begin{array}{l}\text { Deprived } \\
\text { inner city, } \\
\text { high BME }\end{array}$ & $\begin{array}{c}\text { Affluent } \\
\text { metropolitan } \\
\text { outer suburb, } \\
\text { low BME }\end{array}$ & $\begin{array}{l}\text { Affluent } \\
\text { rural, } \\
\text { low } \\
\text { BME }\end{array}$ & $\begin{array}{l}\text { Mixed } \\
\text { city, } \\
\text { high } \\
\text { BME }\end{array}$ & $\begin{array}{l}\text { Mixed } \\
\text { city, } \\
\text { high } \\
\text { BME }\end{array}$ & $\begin{array}{c}\text { Deprived } \\
\text { city, } \\
\text { low } \\
\text { BME }\end{array}$ & $\begin{array}{c}\text { Deprived } \\
\text { mixed } \\
\text { urban/ } \\
\text { rural } \\
\text { low } \\
\text { BME }\end{array}$ & $\begin{array}{l}\text { Deprived } \\
\text { city, } \\
\text { low BME }\end{array}$ & $\begin{array}{c}\text { Deprived } \\
\text { Mixed } \\
\text { urban/ } \\
\text { rural } \\
\text { low } \\
\text { BME }\end{array}$ & $\begin{array}{c}\text { Affluent } \\
\text { rural, } \\
\text { low } \\
\text { BME }\end{array}$ & $\begin{array}{c}\text { Sample } \\
\text { size }\end{array}$ \\
\hline White British & 23 & 87 & 8I & 83 & 60 & 78 & 67 & I27 & II7 & I79 & 900 \\
\hline White Irish & I5 & o & o & I & o & 3 & o & o & o & 3 & 22 \\
\hline Any other White background & 8 & 2 & I & o & 3 & 2 & o & I & I & 0 & I8 \\
\hline Mixed ethnicity & 3 & o & o & I & o & I & o & o & o & o & 5 \\
\hline Asian or Asian British (Indian) & I2 & 3 & o & 43 & 29 & 2 & o & $\mathrm{I} 2$ & o & o & IOI \\
\hline Asian or Asian British (Pakistani) & 2 & 22 & o & 0 & 2 & o & o & o & o & o & 26 \\
\hline $\begin{array}{l}\text { Asian or Asian British } \\
\text { (Bangladeshi) }\end{array}$ & o & o & o & o & o & o & o & IO & o & o & IO \\
\hline Any other Asian background & o & o & o & I & 45 & o & $\mathrm{o}$ & 5 & I & $\mathrm{o}$ & $5^{2}$ \\
\hline $\begin{array}{l}\text { Black or Black British } \\
\text { (Caribbean) }\end{array}$ & $2 \mathrm{I}$ & 2 & o & 4 & I & I & 2 & 5 & o & o & $3^{6}$ \\
\hline Black or Black British (African) & 3 & o & o & 8 & I & 45 & o & 9 & o & o & 77 \\
\hline Any other Black background & IO & o & o & o & o & II & o & o & o & o & IO \\
\hline Chinese & o & o & o & o & o & I6 & o & 7 & o & o & 23 \\
\hline Any other background & I3 & o & o & o & o & o & o & o & o & o & o \\
\hline BME participants & 87 & 25 & I & $5^{8}$ & $8 \mathrm{I}$ & $8 \mathrm{I}$ & 2 & 49 & 2 & 4 & 380 \\
\hline$\ldots$ as a percentage of the total & 79 & o & $<\mathrm{I}$ & o & o & o & 3 & 28 & 2 & 2 & $3^{\circ}$ \\
\hline Total participants & IIO & II 6 & 82 & I4 I & $\mathrm{I} 4 \mathrm{I}$ & I 59 & 69 & I 76 & II9 & I82 & I,280 \\
\hline
\end{tabular}

Note: BEM: Black and ethnic minority. 
not be literate, citing his own Bengali community as an example. He considered that this group suffered from particular health issues and that information about these should be provided using pictures.

In a different locality, all Vietnamese older people's concerns were said by one group representative to relate to language issues, with interpretation in health services a major concern. Although some hospitals had interpreters, we were told that it was difficult to find out what was going on, not just respecting interpreting but also in terms of assimilating information. The example was given of an 'old lady with eye problems who needs to deal with her medication, but can't understand information and if the interpreter doesn't help, she won't absorb the information'. A member of staff of a Vietnamese support organisation suggested that the lack of interpreters to accompany older people to health appointments meant some delayed seeing the general practitioner (GP) and their problems worsened. This Vietnamese group received funds from the local authority to provide general information, advice and welfare benefits, but its worker reported that the staff had insufficient time for the more complex work of social care case conferences or assessment. For this and other groups, the solution to such concerns about accessibility partly justified publicsector decisions to enable minority ethnic groups to develop specialist services. One worker made the point well:

It's the lack of access, not knowing what they are entitled to ... religious and cultural barriers. Take social care, we do home care for Somali elders. The government says that social services should be service-user centred and culturally sensitive.

Similarly, whilst talking about a recently arrived group of older people from Africa, a worker commented on behalf of a member that his main problems were:

Language, [he] doesn't know his way about [and] he has been here less than there years in UK. He has been granted asylum. He gets his information at the Somali Centre. The Centre is the main social support.

\section{Use and experiences of local $\mathrm{NHS}$ or council services}

All participants were asked if they or people they knew well had used NHS or local council services recently. Many older people were very pleased with their treatment. For example, one man who attended a Muslim Club said:

I have had several occasions in hospital; had my leg amputated; several operations. [I've had] great experiences of the health system. Wonderful. So generous. I take 22 tablets a day. It's all free, so humane, so civilized. I'm a great admirer of the institutions of this country; a marvellous country to get old in. 
In contrast, however, staff from black and minority ethnic older people's groups raised a number of concerns. One worker for a Somali carers' group said that local GPs did not refer people to services that might be able to help beyond medical treatment, for example, to housing services. In his words, 'They don't pass people on for advice - they should take this responsibility'. He added that GPs do not relate to his group 'at all ... their role is completely missing ... they don't help with getting people to interpreting or translation services', and that his members needed help making appointments and someone to accompany them, and that this was attributable to general language barriers.

\section{Health and social services support for older people and their families}

The adequacy of support elicited a range of comments. There was appreciation of the support for local community group activity, as examples from African, Indian, Irish and Black Caribbean groups revealed. However, there were concerns about responsiveness and acceptability. For example, one man who was the leader of a Muslim Club said, 'A lot of people are entitled to day care but won't go to existing groups because they don't like the environment'. The precariousness of much voluntary sector funding was highlighted as we contacted local groups to see whether they would be willing to take part in the consultations. In one locality, an Asian women's healthy living group no longer functioned because the local NHS Primary Care Trust had withdrawn its financial support, and no alternative funding had been found. In the same area, the local authority had reduced funding for a lunch club used mainly by Black Caribbean older people.

\section{Treatment of older people and their families by local services}

In addition to the need to improve access to information and issues about funding, other reasons were given for difficulties in accessing services, some of which related to expectations of reception. One member of staff considered that many people who came to London as immigrants during the I950s had faced some level of discrimination and would be unwilling to access council services in later life. Those who actually had direct experience of using services seemed, however, to be more confident that improvements had taken place. As one said, 'There have been tremendous changes in the way that I have been treated in hospital. They used not to talk to you as a person from an ethnic minority but now they will; and there is more care, so there has been improvement'.

A man living in sheltered housing in another part of England reported his confidence in the local system of support: 'If I became ill, I feel that 
the services will be provided by the local authority social services or [they will] transfer me to a home where more help can be provided for me'. Participants raised other concerns, as about having to pay for social-care services (a view shared by many White British participants) or for certain NHS services; for example, the immunisations required when travelling abroad, which were seen as iniquitous. Other more individual comments were made about the police targeting young family members, delayed repairs to local authority housing, and problems with community safety. The latter two points were also made by white British respondents, particularly those living in urban areas (Manthorpe et al. 2006).

\section{The contribution of older people to service planning and development}

The experiences of both minority ethnic group representatives and paid staff demonstrated considerable variation in the ways in which they took part in public engagement processes. One worker said:

The PCT (Primary Care Trust) runs a BME (Black and Minority Ethnic Group) forum but, as far as I am concerned, it is a talking shop. They've just set it up to cover their backs [i.e. to conform to legislation]. This [the local council] is backward as far as race is concerned. How do people find out what's available?

On the other hand, in another area, a worker said:

It's a diverse area. The ethnic minority is not a minority now; we are half of the population. The council is doing its best to provide services taking into account culture, language. ... The council has formed a partnership with a community network looking into needs, how to service the community, consulting. I'm a member of the community network - the network is a body of voluntary organisations.

\section{Discussion}

The participants in the evaluation of the NSFOP countered the stereotypical idea that older people from black and minority ethnic groups are unwilling to take part in consultations (Begum 2006). Indeed, people from these groups were over-represented among those who took part, and it appears that the nominal group methods were acceptable to them and productive, which had not previously been established. Older people and other service users have repeatedly pointed out that inadequate attention to preparation and inadequate funding result in token consultations (Moriarty et al. 2007b). Arranging venues and catering, translation and interpretation, and covering participants' travel and support costs all had implications for the overall budget. Research funders and policy makers 
need to acknowledge that increased expectations about public participation should be accompanied by the necessary funding. It is to the Healthcare Commission's credit that it was prepared to make a considerable financial investment in ensuring diversity in the consultation. Nevertheless and despite the preparation, in many instances it was individuals from local organisations who played an important role in facilitating contacts, thus confirming Simmons and Birchall's (2005) message that people's motivations to participate are strengthened when a request comes from those they trust.

Despite our considerable collective experience of organising these events, there were unanticipated issues. For example, knowing that the prevalence of sight problems caused by conditions such as diabetes, glaucoma, and age-related macular degeneration varies across different ethnic groups should have alerted us to the need to make large print translated versions of publicity material. We had also not anticipated that so many people, irrespective of gender, age and ethnicity, would prefer to participate anonymously. This was a timely reminder that many people are reluctant to describe their experiences of health and socialcare services for fear that it will have consequences for the services they receive or because they believe that the information will be used for other purposes.

Some of the findings will be familiar to those who have followed British debates about ethnicity, ageing and health care, in that they confirm the existence of barriers to service access and acceptability, such as the lack of information, particularly for those who are not fluent in English, and the apparent capriciousness of funding for many community groups. Whilst there were examples of ascribing poor quality of care to an individual clinician's failings, the participants were much more likely to identify deficiencies of the local policy commitment, resource allocation and engagement with minority ethnic issues. The NSFOP stated that there was substantial evidence that minority ethnic older people had difficulties with the accessibility and sensitivity of services. Our findings suggest that the picture is more complex. Services and attitudes were perceived to be improving in areas where the black and minority populations are large or their average ages are rising. Continued scrutiny will be needed to see if such improvements are sustained.

The consultation process also directed attention to the inter-connected issue of language support and the means of accessing information. The need for more interpreters was voiced not only by those who did not speak English well but also more widely by all older people as a requirement for getting better information about systems and services. This corroborates the observation in Alexander, Edwards and Temple's (2004) study of 
interpreters' experiences; namely that interpretation and information roles are entwined. More in-depth research is required to ascertain if, when people refer to interpreters, it is a way of highlighting broader, underlying information and access issues, for example, a sense of feeling distant from social networks (Craig and Rai i996).

We found some differences in the concerns raised by individual older people and group representatives and staff. Older people raised broad issues including housing, policing, transport and community safety. Their concerns about access to services were about navigation through their eligibility for and adjudication within services (Dixon-Woods et al. 2006). The problems of navigation were apparent in the emphasis on information and translation, whilst ideas about candidacy were expressed through discussions of entitlement, and raising awareness of health issues of significance to particular minority ethnic groups. Health and council services' adjudication processes received some praise, with the participants noting positive changes in the ways in which staff approached and addressed them, and dealt with their concerns.

Group representatives and staff in the voluntary and independent sectors were aware of the focus of the NSFOP evaluation and appeared to use it as a vehicle to comment on the commissioning of their own services and level of grant aid. They built up an argument for their services by consolidating the points made by individual older people, especially concerning access and information; they also spoke more directly of the need for cultural sensitivity and their own role as bridges to mainstream services. This echoes the role of voluntary organisations as bridging and bonding capital (Putnam 200o).

\section{Limitations of the study}

We went to great lengths to elicit a range of opinions and experiences that we could treat as representative of older people from minority ethnic groups, by using mixed methods to obtain nuanced and elaborated views. Similarly, we tried to avoid interpretation biases with explicit quality control, involving both external review of the consultation methods and iterative reviews of the findings. The methods were as robust as we could make them for a national study conducted over a few months, and we believe our findings reflect the experiences of older people from minority ethnic backgrounds. We are aware, however, that Curtis and Lawson (2000) reported differences between 'public' and 'private' discourses about health, between what people say publicly and in private. We attempted to minimise this effect by working with older researchers, researchers from black and minority backgrounds, and by collaborating 
with existing, well-established groups. Nonetheless, the role of service user researchers working with older people, particularly those from minority ethnic groups, needs further development.

\section{Conclusions}

It is hoped that new studies and appraisals will draw on our experiences of facilitating participation by diverse groups of older citizens. Our principal recommendations are: to use multiple routes to encourage participation from minority groups, to seek the assistance of black and minority voluntary and community organisations as well as general older people's organisations, and to use well-tried methods of public engagement and public consultation. These methods pay attention to details of access, reimbursement and friendliness, and we believe that our ability to engage minority ethnic older people was achieved in no small measure by the visible presence of older researchers at all events. Black and minority ethnic older citizens are not always hard to reach or hard to hear, particularly where a rich civil society is engaged in the consultation processes. The levels of satisfaction with health and personal social services amongst black and minority ethnic older people were higher than we had anticipated, and than the NSFOP suggested. The concerns were more about the incomplete recognition of the culturally-specific needs of older people from black and minority ethnic groups by mainstream services than about the need to develop separate services for black and minority ethnic older people.

\section{Acknowledgements}

We thank The Healthcare Commission for funding the consultations on which this article is based, and are grateful to those working in the inspection localities that helped arrange listening events, focus groups and interviews. Janet Robinson and Sheila Lakey provided considerable help with the administrative arrangements for the project. Janet James, Jane Reast, Phillip Rapaport, Alan Mitchell, Pauline Weinstein, Liz Price, Peggy Redfern, Wesley Dowridge, Vicki Raymond, Tony Beresford, Fazila Khanji, Maryam Khanji, R. Dave, Joyce Gosse, Tessa Dunning, Lisa Pinkney, Sandra Dowling, Sheila Cornes and Martin Stevens gave additional help with the listening events, focus groups and interviews. Most of all, we thank all the participants for taking the time to share their experiences with us. The Social Care Workforce Research Unit at King's College London receives funding from the Department of Health for England. The views expressed in this article are not necessarily those of the Department of Health or the Healthcare Commission. 


\section{NOTES}

I The studied local authorities were Buckinghamshire, Dorset, Leicester, Liverpool, the London Boroughs of Brent and Greenwich, Medway, Portsmouth, Redcar and Cleveland, and Wiltshire. NHS Trusts are management units. Many are centred on major hospitals, many are Primary Care Trusts, and there are mental health, ambulance service and other specialised Trusts.

2 Ethics approval for the inspectorates' evaluation was not required as their work is a statutory activity but the research team undertaking the consultations abided by principles of informed consent, voluntary participation and confidentiality.

\section{References}

Ahmad, W. I.-U. and Atkin, K. (eds) 1996. 'Race' and Community Care. Open University Press, Buckingham.

Ahmad, W. I. U. and Walker, R. I997. Asian older people: housing, health and access to services. Ageing \& Society, I 7, I, I4I-65.

Alexander, C., Edwards, R., Temple, B., with, Kanani, U., Zhuang, L., Mohib, M. and Sam, A. 2004. Access to Services with Interpreters: User Views. Joseph Rowntree Foundation, York.

Anthias, F. 1992. Ethnicity, Class, Gender and Migration: Greek-Cypriots in Britain. Avebury, Aldershot, Hampshire.

Audit Commission 2004. The Fourney to Race Equality: Delivering Improved Services to Local Communities. Audit Commission, London.

Bainbridge, I. and Ricketts, A. 2003. Improving Older People's Services: An Overview of Performance. Social Services Inspectorate, London.

Begum, N. 2006. Doing it for Themselves: Participation and Black and Minority Ethnic Service Users. Social Care Institute for Excellence/Race Equality Foundation, London.

Blakemore, K. and Bhalla, A. 1979. The Elderly of Ethnic Minorities: A Review of the Literature and Newes of a Research Project in Birmingham. All Faiths for One Race, Birmingham, England.

Bondas, T. 2006. Paths to nursing leadership. Fournal of Nursing Management, I4, 332-9.

Bousetta, H. 2001. Extending Democracy Participation, Consultation and Representation of Ethnic Minority People in Public Life. Centre for the Study of Citizenship and Ethnicity, University of Bristol, Bristol, England.

Butt, J. 2005. Are we there yet? Identifying the characteristics of social care organisations that successfully promote diversity. In Butt, J., Patel, B. and Stuart, O. (eds), Race Equality Discussion Papers. Social Care Institute for Excellence, London, 4-28.

Butt, J. and Mirza, K. 1996. Social Care and Black Communities. Her Majesty's Stationery Office, London.

Butt, J. and O'Neil, A. 2004. 'Let's Move On': Black and Minority Ethnic Older People's Views on Research Findings. Joseph Rowntree Foundation, York.

City of Bradford Policy and Research Unit 1999. Population Estimates and Forecasts: Bradford Metropolitan District. City of Bradford, Bradford, West Yorkshire.

Connelly, N., Forsythe, L. A., Njike, G. and Rudiger, A. 2006. Older Refugees in the UK: A Literature Review. Refugee Council, Age Concern England, Age Concern London and Association of Greater London Women, London.

Coombe, V. I978. Britain's other elderly. New Age, 3 (summer), 9-i .

Craig, G. and Rai, D. K. I996. Social security, community care and 'race': the marginal dimension. In Ahmad, W. I. U. and Atkin, K. (eds), 'Race' and Community Care. Open University Press, Buckingham, I24-43. 
Curtis, S. and Lawson, K. 200o. Gender, ethnicity and self-reported health: the case of African-Caribbean populations in London. Social Science and Medicine, 5o, 3, $365^{-85}$.

Delbecq, A. L. and Van de Ven, A. H. I97I. A group process model for problem identification and programme planning. Fournal of Applied Behavioural Science, 7, 4, 466-92.

Department for Communities and Local Government 2007. Third Sector Strategy for Communities and Local Government. Department for Communities and Local Government, London.

Department of Health 200I. National Service Framework for Older People. Department of Health, London.

Department of Health and Social Security and Welsh Office 1978. A Happier Old Age: A Discussion Document on Elderly People in Our Society. Department of Health and Social Security, London.

Dixon-Woods, M., Cavers, D., Agarwal, S., Annandale, E., Arthur, A., Harvey, J., Hsu, R., Katbamna, S., Olsen, R., Smith, L., Riley, R. and Sutton, A. 20o6. Conducting a critical interpretive synthesis of the literature on access to healthcare by vulnerable groups. BioMed Central Medical Research Methodology, 6, I, 35.

Drennan, V., Walters, K., Lenihan, P., Cohen, S., Myerson, S. and Iliffe, S. 2007. Priorities in identifying unmet need in older people attending general practice: a nominal group technique study. Family Practice, 24, 454-6o.

Gallagher, M., Hares, T., Spencer, J., Bradshaw, C. and Webb, I. I993. The nominal group technique: a research tool for general practice? Family Practice, Io, I, 76-8I.

Healthcare Commission 2006 a. Living Well in Later Life: A Review of Progress against the National Service Framework for Older People. Commission for Healthcare Audit and Inspection, London.

Healthcare Commission 2006 b. Variations in the Experiences of Patients Using the NHS Services in England. Commission for Healthcare Audit and Inspection, London.

Iliffe, S. and Manthorpe, J. 2004. The debate on ethnicity and dementia: from category fallacy to person-centred care? Aging and Mental Health, 8, 4, 383-92.

Jee, M., Popay, J., Everitt, A. and Eversley, J. I999. Evaluating a Whole Systems Approach to Primary Health Care Development. King's Fund, London.

Johnson, P. 2004. Analytic induction. In Cassell, C. and Symon, G. (eds), Essential Guide to Qualitative Methods in Organizational Research. Sage, London, I65-79.

Katbamna, S., Ahmad, W., Bhakta, P., Baker, R. and Parker, G. 2004. Do they look after their own? Informal support for South Asian carers. Health and Social Care in the Community, 1 2, 5, 398-406.

Lashko, G. 2006. Meeting the needs of black and minority ethnic communities. Housing, Care and Support, 9, I, 2-4.

Leamy, M. and Clough, R. 20o6. How Older People Became Researchers: Training, Guidance and Practice in Action. Joseph Rowntree Foundation, York.

Levenson, R. and Meredith, B. 200o. Elders' Health: The Voice of Experience. A Contribution to the Debate of the Age. Age Concern England, London.

Lowdell, C., Evandrou, M., Bardsley, M., Morgan, D. and Soljak, M. 200o. Health of Ethnic Minority Elders in London. Health of Londoners Project, London.

Manning, P. K. I982. Analytic induction. In Smith, R. B. and P. K. Manning (eds), Qualitative Methods. Volume II, Handbook of Social Science Methods. Sage, Cambridge, Massachusetts, 273-302.

Manthorpe, J., Bright, L., Cornes, M., Rapaport, J., Clough, R., Iliffe, S., Moriarty, J. and OPRSI 2006. Commissioning community wellbeing: older people's views. Fournal of Integrated Care I 4, 4, 28-37.

Manthorpe, J. and Klee, D. 2006. Partnership in inspection: lessons from the review of the NSFOP. Journal of Integrated Care, $\mathbf{1 4}, 6,45^{-52}$. 
Manthorpe, J., Iliffe, S., Moriarty, J., Cornes, M., Rapaport, J., Clough, R., Bright, L. and Older People Researching Social Issues 2007. Five years on: older people's views of the National Service Framework for Older People. Age and Ageing 36, 5, 50 - 7 .

Mason, D. (ed.) 2003. Explaining Ethnic Differences: Changing Patterns of Disadvantage in Britain. Policy Press, Bristol, England.

McLeod, M., Owen, D. and Khamis, C. 2001. Black and Minority Ethnic Voluntary and Community Organisations: Their Role and Future Development in England and Wales. Policy Studies Institute, London.

Moriarty, J., Manthorpe, J., Iliffe, S., Cornes, M., Rapaport, J., Clough, R., Bright, L., Lakey, S. and Older People Researching Social Issues 2007a. Using diverse sources of evidence: the role of audit and inspection reports in evaluating progress in the provision of services for people with dementia and their carers. Evidence and Policy, 3, $3,385-405$.

Moriarty, J., Rapaport, P., Beresford, P., Branfield, F., Forrest, V., Manthorpe, J., Martineau, S., Cornes, M., Butt, J., Iliffe, S., Taylor, B. and Keady, J. 2007b. Practice Guide: The Participation of Adult Service Users, including Older People, in Developing Social Care. Social Care Institute for Excellence, London.

Murphy, E., Dingwall, R., Greatbatch, D., Parker, S. and Watson, P. 1998. Qualitative Research Methods in Health Technology Assessment: A Review of the Literature. Health Technology Assessment 2(r6), National Co-ordinating Centre for Health Technology Assessment, Southampton, Hampshire.

National Audit Office 2004. Delivering Public Services to a Diverse Society. Stationery Office, London.

Nazroo, J. Y. 2001. Ethnicity, Class and Health. Policy Studies Institute, London.

Nazroo, J. Y. and Williams, D. R. 2005. The social determination of ethnic/racial inequalities in health. In Marmot, M. and Wilkinson, R. (eds), Social Determinants of Health. Oxford University Press, Oxford, 238-66.

Office for National Statistics 2002. Social Focus in Brief: Ethnicity. Office for National Statistics, London.

Ong, B. N., Humphris, G., Annett, H. and Rifkin, S. I99I. Rapid appraisal in an urban setting, an example from the developed world. Social Science and Medicine, 32, $8,909-15$.

Parry, G., Van Cleemput, P., Peters, J., Moore, J., Walters, S., Thomas, K. and Cooper, C. 2004. The Health Status of Gypsies and Travellers in England. School for Health and Related Research, University of Sheffield, Sheffield, South Yorkshire.

Peach, C. 2005. Caribbean mobility in Great Britain: spatial segregation and intermarriage. In Loury, G. C., Tariq, M. and Teles, S. M. (eds), Ethnicity, Social Mobility and Public Policy: Comparing the USA and UK. Cambridge University Press, Cambridge, I78-203.

Policy Research Institute on Ageing and Ethnicity (PRIAE) 2005. Black and Minority Ethnic Elders in the UK: Health and Social Care Research Findings. PRIAE, Leeds, West Yorkshire.

Putnam, R. D. 2000. Bowling Alone. Touchstone, New York.

Ragin, C. C. I994. Constructing Social Research. Pine Forge, Thousand Oaks, California.

Rait, G. and Iliffe, S. 2003. Care of older people. In Kai, J. (ed.), Ethnicity, Health and Primary Care. Oxford University Press, Oxford, 139-49.

Royal Commission on Long Term Care of the Elderly i999. With Respect to Old Age: Long Term Care: Rights and Responsibilities. Cm 4I92-I, Stationery Office, London.

Ryan, M., Scott, D. A., Reeves, C., Bate, A., van Teijlingen, E. R., Russell, E. M., Napper, M. and Robb, C. M. 2001. Eliciting Public Preferences for Healthcare: A Systematic Review of Techniques. Health Technology Assessment 5(5), National Co-ordinating Centre for Health Technology Assessment, Southampton, Hampshire. 
Secretaries of State for Health and Social Security Wales and Scotland ig89. Caring for People: Community Care in the Next Decade and Beyond. Cm 849, Her Majesty's Stationery Office, London.

Secretaries of State for Social Services, Scotland, Wales and Northern Ireland I98I. Growing Older. Cm 8173, Her Majesty's Stationery Office, London.

Simmons, R. and Birchall, J. 2005. A joined-up approach to user participation in public services: strengthening the 'participation chain'. Social Policy and Administration, 39, $3,260-83$.

Simpson, S. 1997. Demography and ethnicity: case studies from Bradford. New Community 23, I, 89-I07.

Van de Ven, A. H. and Delbecq, A. L. 1972. The nominal group as a research instrument for exploratory health studies. American Fournal of Public Health, 62, 3, 337-42.

Warnes, T., Lowles, R. and Oh, K. M. 2002. Older People in Yorkshire and the Humber. Age Concern in Yorkshire, Rotherham, South Yorkshire.

Warnes, A., Friedrich, K., Kelleher, L. and Torres, S. 2004. The diversity and welfare of older migrants in Europe. Ageing \& Society, 24, 3, 307-26.

World Health Organisation 1992. Guidelines for Rapid Appraisal to Assess Community Health Needs. World Health Organisation, Geneva.

Yu, W. K. 200o. Chinese Older People: A Need for Social Inclusion in Two Communities. Policy Press, Bristol, England.

Address for correspondence:

Accepted 5 March 2008

Jill Manthorpe, Social Care Workforce Research Unit,

King's College London, Melbourne House, 5 th Floor, 46 Aldwych, London $\mathrm{WC}_{2}{ }_{4} \mathrm{LL}, \mathrm{UK}$.

E-mail: jill.manthorpe@kcl.ac.uk 